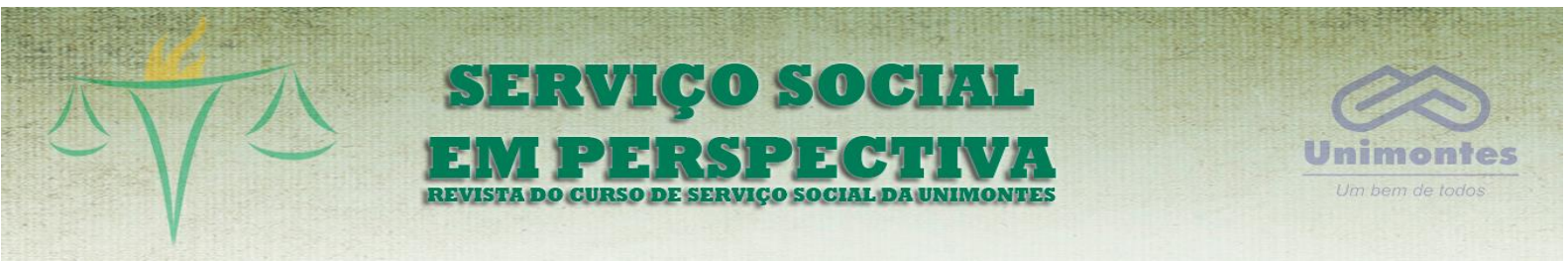

\title{
A RELAÇÃO ENTRE A LUTA ANTIRRACISTA, O VEGANISMO E A POLÍTICA DE ASSISTÊNCIA SOCIAL
}

\section{THE RELATIONSHIP BETWEEN ANTI-RACIST FIGHT, VEGANISM AND SOCIAL ASSISTANCE POLICY}

Rodrigo Felipe Nascimento de Lima ${ }^{1}$

Resumo: $O$ artigo pretende mostrar os contributos e inclinações do protagonismo negro na esfera do veganismo ético, político e interseccional. Exibindo personagens, interlocuções raciais, o comportamento midiático, bem como as tentativas de politização de demandas do veganismo dentro da luta antirracista. Desse modo, o objetivo deste artigo é dar maior visibilidade a lógica da representatividade junto com a problematização do status elitizado do veganismo e, ao mesmo tempo, apontar questões desse enredo de investigação às abordagens do Serviço Social no âmbito da política de assistência social.

Palavras-chave: protagonismo negro; veganismo; política de assistência social.

\begin{abstract}
The article aims to show the contributions and inclinations of black protagonism in the sphere of ethical, political and intersectional veganism. Exhibiting characters, racial interlocutions, media behavior, as well as attempts to politicize the demands of veganism within the anti-racist struggle. Thus, the objective of this article is to give greater visibility to the logic of representativeness together with the problematization of the elite status of veganism and, at the same time, to point out issues of this plot of investigation to the approaches of Social Work within the scope of social assistance policy.
\end{abstract}

Keywords: black protagonism; veganism; social assistance policy.

\section{INTRODUÇÃO}

\footnotetext{
${ }^{1}$ Discente do curso de Serviço Social na Universidade Federal de Pernambuco (UFPE). E-mail: rodriggofelipe1123@gmail.com
} 
A relação entre a luta antirracista, o veganismo e a política de assistência social

Marcelo Braz (2012), em sua obra sobre a mudança no perfil das lutas de classes e modismos conceituais, contextualiza as alterações que vem intercorrendo nas sociedades capitalistas, principalmente nos últimos 40 anos. Naquele momento, para o autor, os anos de 1970, 1980 e 1990 foram estruturais, pois forneceram subterfúgios suficientes para o deslocamento da análise das lutas que se pautavam no trabalho para uma análise centrada em aspectos da contracultura. Sendo assim, a ideologia, as questões ecológicas, de raça, gênero e entre outras coisas mais se evidenciaram. No Brasil, ainda segundo o autor, estes anos trespassaram os questionamentos - ou mesmo o abandono - "da noção que atribui à classe operária a condição de sujeito político revolucionário" (Braz, 2012, p.138), o que culminou em alterações no debate teórico sobre os movimentos sociais no Brasil e no próprio protagonismo de novos movimentos sociais. Essas circunstâncias vêm enxergando diferentes quadros, destacando-se o emprego, cada vez maior, das contribuições e movimentos do protagonismo negro afeiçoado ao veganismo.

Nesse prisma, é necessário dizer que a compreensão objetiva a respeito do veganismo ultrapassa o fundamento depreciativo na qual o movimento vegano e/ou vegetariano é cerceado apenas a pessoas brancas e elitizadas. Aqui, persevera-se 0 entendimento conservador que parte da representação seja executada pela população branca. No entanto, tendo em vista a situação de segregação racial tomada pelo preconceito e por declarações beligerantes na sociedade, a imagem dos "veganos brancos convencionais" prevalece, haja vista os disfarces das relações sociais e do controle do poder que subsiste em nossa sociabilidade decorrente do racismo historicamente estruturado e da sequente invisibilidade construída. Isto é, a marcha nesta ocasião não é na investida de infiltrar-se no mundo da supremacia branca. Pelo contrário, o despertar aqui está para a ressignificação e o alçar do ativismo negro em contribuir com sinergia para a causa dos direitos dos animais como uma forma de processo de conscientização sobre o especismo da humanidade nas relações de dominação, nas quais os animais não humanos são vítimas recorrentes de um holocausto animalesco em benefício à sociedade capitalista industrial baseada na exploração intensa dos recursos naturais para a criação de gado e na constante decomposição da fauna e flora. 


\section{A relação entre a luta antirracista, o veganismo e a política de assistência social}

Tendo isso em vista, é chegada a hora de mostrar os elementos da representatividade negra dentro do movimento vegano e/ou vegetariano e incentivar a todo momento alguém da comunidade vegana o quão importante é a junção da comunidade negra ao veganismo. Isso porque, não basta apenas saber em tese que homens e mulheres negras pleitearam para conquistar espaços de autonomia, mas é preciso evidenciar a ainda luta na contemporaneidade pela composição de seus projetos como protagonistas da história. Diante disso, veganos negros refletem sobre os alimentos que colocam dentro do próprio corpo, e como ainda hoje faltam rostos pretos nas imagens de propagandas do movimento, haja vista que "Alicia Silverstone pode ser a garota-propaganda do veganismo contemporâneo, mas a maioria das pessoas esquece que Erykah Badu também é vegana" (JUSBRASIL, 2015). Sendo assim, a intenção desse artigo é fazer com que ele possibilite um espaço de apreciação, leitura e reflexão onde veganos negros possam absorver mais histórias de outros veganos negros, e que também outros indivíduos que não são veganos possam sentir-se à vontade em conhecer mais sobre esse modo de viver caso queiram, pois esse artigo é um instrumento de crítica e que contribui a pensar mais para com esse tema no âmbito das relações sociais.

\section{CONTEXTUALIZANDO AS PERSPECTIVAS DO RACISMO, VEGANISMO E SERVIÇO SOCIAL}

A prática do veganismo e/ou vegetarianismo ${ }^{2}$ hodiernamente trata do especismo, na qual é um pressuposto que a espécie humana é livre para explorar e matar outras espécies, uma vez que as consideram inferiores. Infelizmente, nossa sociedade ainda é bastante acomodada aos costumes, costumes estes que não abalam os grupos políticos e econômicos dominantes e que tornam os animais meras mercadorias para consumo. Com isso, o veganismo, por ser um modo de

\footnotetext{
${ }^{2}$ Segundo a SVB (2019), o veganismo busca excluir, na medida do possível e praticável, todas as formas de exploração e crueldade contra os animais - seja na alimentação, no vestuário ou em outras esferas do consumo. Quando, neste trabalho, o termo "vegetariano" ou "vegetarianismo" aparecer, estes se referem necessariamente à alimentação.
} 


\title{
A relação entre a luta antirracista, o veganismo e a política de assistência social
}

viver, traz uma nova percepção da realidade ao passo que busca revelar as máscaras das indústrias e de nós mesmos sobre os animais, haja vista que é cômodo ignorar o sofrimento destes. Desse modo, a população negra através de diversas produções culturais, vem empenhando-se em descontruir a perspectiva de que é um grupo social excluído para com essa temática, e se inspira na análise política, eco crítica e antirracista para propagar a luta contra o especismo. Sendo assim, já para incitar esse debate, a Sociedade Vegetariana Brasileira (2018) publica:

\begin{abstract}
O salto surpreendente no número de pessoas que exclui alimentos de origem animal de seu cardápio reflete tendências mundiais consolidadas de busca por uma alimentação mais saudável, sustentável e ética. Por um lado, o reconhecimento dos benefícios de uma alimentação vegetariana para a saúde é cada vez maior, com grandes organizações - como a Organização Mundial de Saúde - se pronunciando sobre os riscos do consumo elevado de carnes. Por outro lado, o crescimento no número de pessoas que opta por excluir as carnes e derivados do cardápio, ou reduzir seu consumo, é impulsionado pela preocupação crescente da população com os impactos de seus hábitos de consumo. Dentre estas, estão as preocupações com o impacto ambiental negativo da pecuária e a indignação com as condições de vida impostas aos animais usados nos processos de produção. De fato, uma pesquisa do Datafolha de 2017 já havia mostrado que $63 \%$ dos brasileiros quer reduzir o consumo de carne. (SVB, 2018)
\end{abstract}

Partindo desse ponto de vista, no ano de 2015 era fundada pela primeira vez a plataforma Black Vegans Rock ${ }^{3}$ - Veganos Negros São o Máximo - pela produtora de mídia digital Aph Ko, a qual a autora "decidiu pesquisar e compilar uma lista de veganos negros influentes que estavam fazendo um trabalho incrível para desmantelar o estereótipo que o veganismo era coisa de pessoa branca" (KO, 2015). É inegável que a lista obteve êxito, recebendo centenas de milhares de emails de veganos negros ao redor do mundo, a qual realça, conecta e informa veganos negros diariamente a fim de impulsionar a representatividade negra dentro do movimento vegano e modificar a convencional narrativa colocada. Dessa maneira, vale lembrar que o aparecimento dessa plataforma mostra como a representatividade torna-se essencial para quebrar costumes retrógrados e atos inerciais. Isso porque, segundo o ovacionado site de notícias Huffpost, há o crescente esforço de poucas organizações em destacar os veganos negros. A

\footnotetext{
${ }^{3}$ Como fonte de acesso e para mais informações, acessar o site: http://www.blackvegansrock.com/.
} 


\title{
FELIPE, R. \\ A relação entre a luta antirracista, o veganismo e a política de assistência social
}

$\mathrm{PeTA}^{4}$, por exemplo, trabalhou com veganos negros influentes, tais como o rapper RZA, e o humorista Dick Gregory. Contudo, apesar dos avanços, o "rosto" mais conhecido do veganismo permanece muito branco. Para complementar esse debate, Aph Kho vai afirmar:

\begin{abstract}
os veganos negros são ignorados por partes do mundo vegano. [...] A defesa dos direitos dos animais começou a virar praticamente uma 'identidade racial' para pessoas brancas. Então, quando negros se envolvem nesse movimento, os brancos começam a nos falar o que é certo e errado. E isso impede muitos negros de avançar. A gente começa a perceber que alguns negros seguem uma trajetória diferente para chegar à defesa dos direitos dos animais ao veganismo, um caminho que passa pelo antirracismo. (KO apud TERTO, HUFFPOST NEWS, 2017)
\end{abstract}

Por meio da análise supracitada, o desencorajamento em adentrar ao veganismo ainda é um iminente grave, onde consegue ilustrar preconceitos e propagar uma imagem de um estilo de vida privilegiado, a qual este último não é. Infelizmente, prova desse preconceito foi o acontecimento referente ao Supremo Tribunal Federal neste ano em colocar em pauta o tema da criminalização ao abate animal, a qual variantes do movimento vegano com declarações racistas entraram em conflito com o movimento negro no que diz respeito às religiões de matriz africana, as demonizando cada vez mais. Desse modo, encontrar corpos subalternos erguendo a bandeira do veganismo ainda é um desafio, mas que vem progressivamente sendo desconstruída com a presença e cooperação da população negra. Tal fator é real, haja vista que segundo a cientista social e ativista negra e vegana Nataly $\mathrm{Neri}^{5}$ (2019), a causa animal é fundamental, pois não consegue vislumbrar a libertação de gênero ou racial em uma sociedade especista, que crê cegamente que uma espécie é superior a outra e, por isso, a exploração animal é natural. Para a autora, estimular a causa animal é importante, pois encoraja a repensar as pseudonecessidades que a sociedade carnista impõe sobre a carne e laticínios. Nesse molde, sobre o caso do STF, a mesma autora comenta:

\footnotetext{
${ }^{4}$ People for the Ethical Treatment of Animals/Pessoas Pelo Tratamento Ético dos Animais (PeTA) é uma organização não governamental de ambiente que se empenha nos direitos dos animais.

${ }^{5}$ A autora possui um canal no Youtube com mais de meio milhão de inscritos chamado "Nátaly Neri" e compartilha seus processos de autonomia ao falar sobre raça, gênero, sociedade, sustentabilidade. Para acesso: https://www.youtube.com/channel/UCjivwB8MrrGCMlluoSdkrQg.
} 
FELIPE, R.

A relação entre a luta antirracista, o veganismo e a política de assistência social

O ponto não é "ser ou não ser" a favor do abate animal, [...] a pauta é sobre a constante estigmatização e tentativa de criminalização que vem sofrendo as religiões de matriz africana no Brasil. Não é sobre tornar legal o sacrifício animal, é sobre evitar que apenas religiões que já são perseguidas por conta do racismo sejam criminalizadas por uma prática que é comum a todas as outras religiões do Brasil, inclusive em maior escala o cristianismo. [...] O ponto é contra a perseguição religiosa. (NERI, 2019)

Com essa postura, é preciso notar que o veganismo é igualmente capaz de ser antirracista e lutar em combate contra toda opressão animal, e a população preta e vegana crescente é prova disso. Não é negar sua etnia ou toda sua história, uma vez que culturas e tradições se transformam ao longo do tempo impulsionadas pelas mudanças geracionais, temporais e informacionais. Não é um processo de aculturação de perca de raízes. O molde é baseado no questionamento e na luta pela libertação humana e dos animais não humanos. É sobre pessoas dentro de sua própria religiosidade buscando informações sobre suas próprias raízes, questionando e oferecendo novas postulações, não reproduzindo um "veganismo ocidental". É importante ressaltar que a interlocução se forma nas críticas aos grandes abatedouros e a pecuária que faturam milhões diariamente com a morte e sofrimento animal resultantes do modo de produção capitalista, baseado na infindável exploração. O movimento negro articulado ao movimento vegano abraça as diferentes religiosidades e prossegue contra a concepção que seres humanos são superiores a animais. (NERI, 2019)

Em razão disso, o veganismo não é uma tentativa de modificar os cultos ou criticar pejorativamente rituais, mesmo que alguns membros do movimento o façam infelizmente; sendo essa inclusive uma das causas que afasta a população negra diante do veganismo. Nessa ocasião, o entendimento mais sensato é discernir vida pessoal com religiosa e mostrar que o veganismo não muda ou the afasta de sua fé, pois há indivíduos veganos ligados as suas diversas religiões, em especial quando debate-se o veganismo no candomblé (llustração 1). A soul food ${ }^{6}$, por exemplo, faz parte da alimentação da comunidade afro-americana, a qual o consumo da carne é

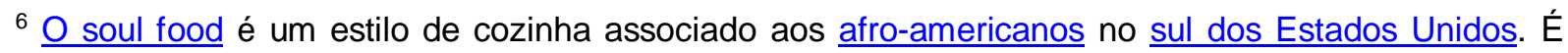
comum em áreas com presença histórica de afro-americanos e tem sido um elemento cultural entre as comunidades afro-americanas. (Wikipedia, 2019)
} 
FELIPE, R.

A relação entre a luta antirracista, o veganismo e a política de assistência social

uma tradição que significa resiliência, força e abundância. Entretanto, negros veganos produziram a versão soul food vegan ${ }^{7}$ a fim de produzir comida vegana que combata deficiências nutricionais da comunidade negra e que também significa resiliência, força e abundância.

\section{Ilustração 1}

\section{DEPOIMENTOS:}

Mike Meneghetti é iniciado há 29 anos e já faz 5 anos que ele resolveu se tornar vegano. Mike diz que não encontrou barreiras para unir seu estilo de vida vegano com o culto candomblecista e afirma ter total apoio de seus filhos e comunidade. E por fim, ele ainda concluiu: "Pelo Òrìsà faço qualquer coisa".

Matheus é iniciado há 14 anos e é vegano há 6. Ele decidiu optar pelo veganismo após ir a uma vaquejada e ver como os animais eram maltratados antes do evento acontecer. Ele ainda diz que no começo teve dificuldades em conciliar a sua filosofia de vida com a religião: "Cogitei escolher entre o veganismo e o candomblé porque pra mim não fazia sentido ser vegano e do candomblé. Então me culpava por ser vegano e ser de uma religião onde tem o sacrifício animal e do outro lado me culpava por ser do candomblé e pensar em sair por não concordar com os fundamentos na época". Depois de muito pensar o que fazer, Matheus resolveu que conseguiria conciliar suas duas paixões. Dentro da sua casa de santo ele participa de todas as funções e procura sempre respeitar os animais assim como na sua vida pessoal.

Fonte: Filhos do Candomblé, 2019.

\footnotetext{
${ }^{7}$ Para mais informações sobre a "soul food vegan", acessar: https://soulfoodveganhtx.com/.
} 


\title{
FELIPE, $R$. \\ A relação entre a luta antirracista, o veganismo e a política de assistência social
}

Outra informação valiosa que auxilia esse debate é o acarajé, símbolo da culinária afro-brasileira tradicionalmente vegano: massa de feijão-fradinho, cebola e sal, frita em azeite de dendê. Em outras palavras, não é conveniente a iniciativa de intitular "acarajé vegano", pois tal formulação é dispensável. Nesse horizonte, o protagonismo preto e vegano é se afirmar nos próprios espaços e governar suas agências como ativistas negros e veganos numa sociedade marcada pela subalternização, a fim de fortificar e reafirmar o conhecimento de sua generis, evitando modismos epistemológicos baseados no apenas "é ou não vegano?". É posicionar que somos também criadores. A empreendedora baiana Mona Soares ${ }^{8}$ (2019) explana:

\begin{abstract}
Não há necessidade de dizer "acarajé vegano". Ainda hoje seus elementos de preparação se conservam iguais à forma como era feito em Àfrica em 1600. Por essência, o acarajé é um elemento vegetal. Qualquer coisa acrescentada é complemento e pode ser dispensada. (SOARES, 2019)
\end{abstract}

Outra lacuna dessa nova área de estudos e pesquisas diz respeito ao papel feminino nas discussões sobre o veganismo que também engloba as compreensões de gênero, raça e classe. Thallita Floripes ${ }^{9}$ (2017) vende comida vegana congelada por um valor acessível e atribui sentido ao veganismo com uma perspectiva crítica: "O veganismo é vendido pra elite. Só que tem uma coisa. Tem gente aqui inquieta tentando mudar esse quadro. Tem gente da favela que trabalha com comida vegana" (FLORIPES apud PENINA, NMP, 2017). Assim sendo, e apoiando-se em sua análise, pode-se dizer com indubitabilidade que propalar o veganismo na periferia é necessário e possível, pois ainda existe uma mistificação sobre tal tema em razão da ilusão da carne. Dito isso, a Indústria da Carne ${ }^{10}$ tenta tornar verídico

\footnotetext{
${ }^{8}$ Sua conta no Instagram é @monasoars, a qual compartilha a informação supracitada sobre o acarajé e seu processo de produção em um "destaque", além de mostrar outros aspectos de sua ancestralidade africana nas postagens.

${ }^{9}$ Thallita Floripes (@thallitaxavier) é estudante, negra, ativista vegana e moradora da comunidade do Caramujo, em Niterói, no Rio de Janeiro. É também chef do $1^{\circ}$ buffet de Gastronomia Vegana do Rio de Janeiro apelidado "Banana Buffet" e possui o respectivo blog: meucorponegro.blogspot.com.

${ }^{10}$ Para um entendimento mais abrangente sobre a indústria da carne e seus impactos na alimentação humana e para a devastação do nosso planeta, verificar os documentários: Cowspiracy; $A$ carne é fraca e Domínio. Todos os três documentários são facilmente encontrados na plataforma Youtube.
} 
A relação entre a luta antirracista, o veganismo e a política de assistência social

que o consumo de produtos de origem animal, sobretudo da própria carne, é vital à nossa sobrevivência, a qual regularmente enrijece o status social e nutricional de que é preciso ter carne cotidianamente em vossas mesas, pois também significa estar bem financeiramente. Essa fábula lamentavelmente delonga a ser desmascarada nas comunidades e periferias, pois somos persuadidos sutilmente que esse consumo é necessário, obscurecendo a forma cruel, insustentável e quão maléfico à saúde pode ser.

Além do mais, proceder essa temática é discutir a empatia com animais não humanos, e perceber que somos educados a ter a nossa paixão seletiva a não maltratar exclusivamente gatos e cachorros. À vista disso, a Thallita do exemplo acima conduz e transferi cada vez mais todos esses elementos para a periferia, e isso mostra que existem sim pessoas veganas e da favela que já desvendaram o que acontece na indústria da carne. Mas não é apenas a Thallita. Angela Davis (2012) declara na 27ํㅡ Conferência Empowering Women of Color que a falta de envolvimento crítico que temos com o alimento e com os animais demonstra a magnitude que a lógica do mercado se tornou e envolve Karl Marx, uma vez que o debate não se vai além da concepção do valor de troca do objeto real. Isto é, não pensamos nas relações que esse objeto representa ou perpassa, as quais estas relações foram importantes para a produção desse mesmo objeto. Ainda na Conferência, Davis declamou-se vegana e informou:

\footnotetext{
Acho que é o momento certo para falar sobre isso, porque faz parte de uma perspectiva revolucionária - como podemos não apenas descobrir relações mais compassivas com os seres humanos, mas como podemos desenvolver relações compassivas com as outras criaturas com quem compartilhamos este planeta e isso significaria desafiar toda a forma industrial capitalista de produção de alimentos. (DEVIS, 2012 apud HOCHSCHARTNER, COUNTERPUNCH, 2014)
}

Outrossim, é lamentável observar majoritariamente restaurantes que cobram caro, mesmo que o custo da preparação da comida vegana não o seja. Isso acaba por levar no modismo de que comida vegana ou vegetariana é "coisa de status pra rico", afastando as pessoas para com a causa, em especial das favelas e periferias. Além disso, eventos, restaurantes e conferências encontram-se em sua maioria nas áreas privilegiadas de renda mais alta das grandes cidades. Em Recife, por 


\section{FELIPE, $R$. \\ A relação entre a luta antirracista, o veganismo e a política de assistência social}

exemplo, temos o restaurante VeganU, localizado no bairro nobre da Madalena ou a doceria vegana Pandas Bárbaros situada em Boa Viagem. Ou seja, ainda há a concentração desses estabelecimentos nas "zonas sul" do país. Entretanto, por outro lado, o crescimento dos empórios com a venda de produtos naturais, muitos livres de agrotóxicos e com baixo preço são grandes aliados para o acesso a produtos de origem vegetal que fornecem os nutrientes que o ser humano precisa. Para complementar o que foi dito, Thallita Floripes explica:

\footnotetext{
fazer receitas sem a carne é a coisa mais fácil do mundo. Arroz, feijão, refogar legumes, tudo super básico e barato. Alguns embutidos e industrializados veganos são caros, mas a alimentação natural, comprada toda em sacolão é supereconômica e fácil! [..] O que torna a vida de um vegano favelado mais difícil é consumir comida fora da favela. Você se sente um verdadeiro peixe fora d'água! (FLORIPES apud PENINA, NMP, 2017)
}

Por ter essa reputação de o veganismo ser "coisa de gente branca", atrair a população não-branca para esse espaço torna-se ainda uma dificuldade. Além disso, as campanhas midiáticas feitas em volta do veganismo muitas vezes não 0 circundam como um movimento político capaz de findar todo o abuso e exploração animal, mas como uma espécie de dieta saudável que acaba por perdurar cada vez mais o padrão de beleza da mulher branca e magra, impulsionando essas mesmas pessoas brancas a ganharem mais crédito e atenção nas campanhas pelo "direito dos animais". Em contrapartida, o site Modefica (2017) publicou uma matéria traduzida do site Everyday Feminism afirmando que existem pessoas negras veganas que defendem o veganismo como uma ferramenta própria contra a supremacia branca, e que sentem a importância de discutir sobre o corpo dos animais quando se discute opressão. Isso porque, e como dito, quando o aparelho da mídia propaga o veganismo e alimentação saudável, o foco é direcionado a pessoas brancas privilegiadas, ignorando os corpos negros e dos animais, enfatizando o veganismo a uma mera questão estética.

A matéria ainda traz uma dura crítica, a qual veganos não-brancos lutam contra um sistema alimentício racista que visa a eliminação de uma pessoa negra em cada refeição nas regiões urbanas de baixa renda. Isso acontece por causa da ausência de uma educação para a saúde nessas regiões e de opções limitadas de 


\title{
FELIPE, R. \\ A relação entre a luta antirracista, o veganismo e a política de assistência social
}

comida, e que se tem um foco nas grandes redes de fast-foods, o que pode ser uma forma de discriminação com corpos negros. Logo, comer comidas com baixos nutrientes e ruins aliado com produtos tóxicos de origem animal advindas da indústria da carne é resultado de um sistema racista. Desse modo, alimentar-se de comidas saudáveis é um ato político e ativista contra esse sistema alimentício e é uma forma de combater problemas de saúde da comunidade negra popular, na mesma medida que a comunidade se questiona sobre o próprio consumo da carne, uma vez que existe um ser oprimido e que também sente dor, mas que no final das contas é abatido para a alimentação humana. Como exemplo para esse debate, tem-se a plataforma Sistah Vegan Project ${ }^{11}$ que discute como a comida pode ser um utensílio para as pessoas negras descolonizarem seus corpos. Vale acentuar que essa plataforma foi edificada por uma mulher negra, feminista e vegana chamada Dr. Amie Breeze Harper, a qual é uma famosa estudiosa interseccional sobre veganos negros e consumo consciente. Como elemento agregador, a Sociedade Vegetariana Brasileira (2019) reitera:

\begin{abstract}
Os estudos populacionais que comparam grupos vegetarianos e não vegetarianos com estilo de vida similar mostram que os vegetarianos têm menor incidência de todas as doenças crônicas não transmissíveis, como dislipidemias (alteração dos lipídios no sangue), hipertensão, cardiopatia isquêmica (infarto agudo do miocárdio), diabetes, diversos tipos de câncer e obesidade. Um padrão de alimentação que promove tantos benefícios não pode ser constituído de uma dieta carente. [...] A dieta vegetariana bem planejada, como deve ser qualquer dieta, pode e oferece todos os nutrientes que precisamos. (SVB, 2019)
\end{abstract}

Nesse prisma, como o vegetarianismo e o veganismo são práticas cada vez mais difundidas na sociedade, têm-se a relevância de discutir sobre a Política Nacional de Segurança Alimentar e Nutricional (PNSAN) ${ }^{12}$. Esta, é uma demarcação histórica advinda das lutas sociais pela alimentação como um direito social no Brasil,

\footnotetext{
${ }^{11}$ Para consultar a plataforma, acessar: http://sistahvegan.com/.

12 Segundo o Conselho Nacional de Segurança Alimentar e Nutricional (CONSEA, 2009): objetivo geral da PNSAN é assegurar o direito humano à alimentação adequada a todas e todos habitantes do território brasileiro, promovendo a soberania e a segurança alimentar e nutricional de modo que tenham acesso regular e permanente a alimentos de qualidade, em quantidade suficiente, sem comprometer 0 acesso a outras necessidades essenciais, tendo como base práticas alimentares promotoras da saúde, que respeitem a diversidade cultural e que sejam ambiental, cultural, econômica e socialmente sustentáveis.
} 


\section{FELIPE, R. \\ A relação entre a luta antirracista, o veganismo e a política de assistência social}

uma vez que conquistada pela classe trabalhadora, pois sabe-se que não existe direito outorgado, mas sim conquistado. Sendo assim, no âmbito do Serviço Social essa temática não escapa e está atrelada a garantir o acesso a alimentação de qualidade de forma mais continuada para aqueles que são vulneráveis socialmente, onde a insegurança alimentar ainda acomete e impede o acesso amplo de bens e serviços necessários à existência humana. Ou seja, se a alimentação é um direito social, assistentes sociais têm o papel fundamental de multiplicar esse conhecimento em companhia das famílias e da comunidade.

Desse modo, com auxílio dos Centros de Referência de Assistência Social (CRAS) $)^{13}$, programas e seminários que abarcam a Educação Alimentar e Nutricional são necessários para propalar o conhecimento de hábitos alimentares para uma vida saudável. Sabe-se que saúde envolve o atendimento das necessidades biológicas, mas também é educável. É preciso informar as razões que causam a insegurança alimentar e nutricional no país, e compreender a respeito do vegetarianismo e/ou veganismo pode ser fundamental para combater essa problemática ao expor a procedência dos alimentos que consumimos hoje. Essa questão pode redimensionar o fator da empatia para com os animais não humanos ao mesmo tempo que tenta combater esse sistema alimentício racista para que famílias, grupos e comunidades de baixa renda, em especial, tenham suas refeições e necessidades biológicas atendidas. Posto isto, a Secretaria de Estado da Assistência e Desenvolvimento Social do Estado de Alagoas publica:

\footnotetext{
As ações de Educação Alimentar e Nutricional buscam promover a segurança alimentar e nutricional por meio de ações educativas que levem a práticas alimentares mais adequadas, permitindo às pessoas selecionar e consumir alimentos saudáveis e nutritivos, valorizando a diversidade dos produtos regionais e as vantagens de se aproveitar os alimentos integralmente, reduzindo o desperdício. Com isso, procura-se também resgatar tradições alimentares e sensibilizar a população para a garantia do direito humano a alimentação adequada e saudável em todas as fases do ciclo da vida. Neste sentido as estratégias educativas incentivadas visam a autonomia do indivíduo e a mobilização social, o respeito e a valorização das especificidades culturais. (SEADSAL, 2019)
}

13 O Centro de Referência de Assistência Social (CRAS) é uma unidade pública estatal descentralizada da Política Nacional de Assistência Social. (PNAS). Atua como a principal porta de entrada do Sistema Único de Assistência Social (Suas), dada sua capilaridade nos territórios e é responsável pela organização e oferta de serviços da Proteção Social Básica nas áreas de vulnerabilidade e risco social. 
Por fim, uma das temáticas essenciais dentro do veganismo negro é quebrar com o racismo que coexiste. No movimento pelos direitos dos animais, ainda é comum pessoas negras serem comparadas com animais para justificar uma sensibilidade para com estes últimos. Isto é, são comparadas as opressões que os animais sofrem atualmente com a escravidão que outrora aconteceu nas Américas. Todavia, é indispensável recordar que a opressão racial ainda não se findou, e comparar as opressões pode ser perigoso e racista, pois o "lado branco" (não todos) do veganismo ainda permanece muito quieto quando precisa-se pautar sobre o trabalho antirracista e outras injustiças raciais, mas estes usam-se do escravismo para favorecer o debate dos direitos dos animais infelizmente. Com isso, os ativistas negros veganos direcionam as intersecções de maneira sistemática no debate sobre a violação dos corpos dos animais e sobre o racismo, evitando comparar essas opressões, pois isso desumaniza um movimento e animaliza outro. Para além disso, é destacável que os negros ainda são rotulados como animais, prática racista para desonrar sua imagem e que legitima a serem objetificados, abusados e mortos. Nesse prisma, ativistas veganos negros combatem esse pensamento ao mesmo tempo que se questionam o porquê de animais não-humanos ainda serem objetificados, abusados e mortos, pois "não faz sentido ancorar nosso respeito e humanidade ao desrespeito de um outro grupo de seres". (MODEFICA, 2017)

Para encerrar este artigo, mostrarei um depoimento intitulado "Não é fácil ser jovem, negra e vegana" originalmente publicado pela Agência de Notícias de Direitos Animais (ANDA) que está logo abaixo, e que se encontra no site JUSBRASIL (2015), e para mais, verificar a llustração 2:

Ser vegano não nos faz menos negros. Minhas raízes africanas não começaram a desaparecer quando parei de comer queijo e bacon. Pessoas negras são tão variadas quanto qualquer outro grupo étnico e não devem ser adicionadas às conversas veganas como se fosse um suvenir, mas como membros da comunidade com contribuições a dar. Prince, Angela Basset e o senador de New Jersey Cory Booker são negros e veganos e eles devem ter tanta visibilidade quanto Gwyneth Paltrow ou Moby. [...] Você não tem que escolher entre se importar com questões relacionados a ser negro e se importar com direitos animais. Com a morte de Eric Garner, Mike Brown e Tamir Rice, entre outros, 2014 tem sido um ano difícil para a comunidade negra. Quando eu olhava meu mural e via pessoas postando mensagem de solidariedade com a hashtag \#blacklivesmatter, eu percebi que, apesar de que muitos negros veganos estavam expressando seu repúdio, só alguns poucos 
FELIPE, R.

A relação entre a luta antirracista, o veganismo e a política de assistência social

veganos brancos não ficaram calados. A comunidade que eu abracei e defendi totalmente sem hesitação não fez o mesmo pela minha comunidade, o que me deixa confusa e magoada. (JUSBRASIL, 2015)

\section{Ilustração $2^{14}$}

Só por que você é vegano não significa que você não vai ouvir reclamações por apropriação cultural. A negritude é apreciada pelos brancos há tempos como forma de entretenimento, dos minstrel shows a Iggy Azalea, mas não como algo que valesse a pena ser abraçado e estabelecer um diálogo intelectual. Recentemente, o casal branco Michelle David e Matt Holloway criaram um site vegano chamado Thug Kitchen. As críticas choveram rápido por que as pessoas acharam que eles estavam fazendo uma apropriação indevida da cultura negra para se promover - 0 site vinha cheio de letras de rap, gírias e xingamentos junto com as receitas veganas. Ativistas veganos como Bryant Terry a Breeze Harper criticaram o casal, mas David e Holloway decidiram não participar de nenhum diálogo aberto.

Muitas pessoas me olham de um jeito cético quando eu digo que estou vivendo um estilo de vida com base em plantas. Já notei que veganos brancos em particular costumam responder com algo como "Uau que legal, estou muito orgulhoso de você", como se eu estivesse fazendo algo impressionante. Mas de acordo com o mesmo estudo que eu citei mais acima do Vegetarian Research Group, só $3 \%$ dos americanos brancos se identificam como vegetarianos ou veganos, comparados a $6 \%$ dos negros. Quando a proporção de negros adotando uma dieta vegana é o dobro da de brancos, não seria eu que deveria ficar surpresa e orgulhosa de você?

Fonte: JUSBRASIL, 2015.

\section{CONSIDERAÇÕES FINAIS}

${ }^{14} \mathrm{O}$ dado citado no depoimento dessa ilustração é o seguinte: de acordo com um estudo feito em 2012 nos Estados Unidos pelo Vegetarian Resource Group, 2,5\% dos americanos são veganos. (JUSBRASIL, 2015) 
Pode-se perceber que há uma miríade de veganos não-brancos pelo mundo, mas ainda pode subsistir a dificuldade de uma maior interlocução entre estes. Para isso, é imprescindível acoplar negros e outros grupos étnico-raciais para que o reconhecimento no movimento vegano se torne cada vez mais amplo. Essa imersão consegue estabelecer um vínculo de grande conexão e distende o debate sobre 0 veganismo para outras esferas, tais como a luta pela igualdade racial e o desafiar para com a supremacia branca conservadora. O compartilhamento de experiências culturais dentro da comunidade negra no veganismo vem acontecendo, a plataforma Black Vegans Rock, como citada, é um exemplo disso, na qual quebra com o sentimento solitário de veganos não-brancos dentro da "bolha branca" que o veganismo pode parecer. Juntos, os grupos étnico-raciais fortalecem os cenários desses fluxos culturais e levam conhecimento sobre restaurantes, roupas, eventos, conferências veganas, etc,. os protagonizando da mesma forma.

Por conseguinte, é indubitável que vivemos num regime da morte, onde animais não-humanos são explorados por toda uma engenharia capitalista que transformam estes animais em mercadorias, ignorando seus desejos, instintos e liberdade. Apenas tem valor diante da lógica de mercado, e isso no modo de produção capitalista não poderia ser diferente, uma vez que esta edifica-se pela exploração do trabalho humano e não-humano. Com isso, o especismo, bem como o classismo, sexismo e especialmente o racismo, são questões estruturais que acompanham a sociabilidade capitalista.

Para além disso, este artigo também é uma forma de contribuir para os avanços em pesquisas sobre o tema do veganismo na área do Serviço Social, pois possui uma conexão contundente sobre temáticas como exploração e capitalismo, além de tratar sobre a importância de o (a) Assistente Social estar preparado a se posicionar, opinar e acolher o praticante do veganismo e/ou vegetarianismo com questões que possam envolver segurança e educação alimentar, visto que daqui em diante o vegetarianismo e veganismo tendem a crescer nas diferentes classes e camadas sociais não apenas como questão de saúde, mas como questão ética, ecológica e societária. 


\section{A relação entre a luta antirracista, o veganismo e a política de assistência social}

Enfim, como elemento de intertextualidade, tem-se o artigo intitulado "Ações afirmativas: polêmicas e possibilidades sobre igualdade racial e o papel do Estado" (SANTOS, et al., 2008) que fortifica esse debate ao trazer a ideia que a luta social é uma forma de conquistar direitos, tais como o movimento sufragista, na qual as mulheres almejavam o direito eleitoral, e o movimento dos negros, pela igualdade racial e contra o racismo. Desse modo, o movimento negro vegano é também uma luta social, e visa impedir um ciclo de violência com a total libertação para com os corpos humanos e dos animais não-humanos, pois estes últimos também são seres de senciência. Sendo assim, é de grande valor e prestígio o papel do protagonismo negro no veganismo, e atores sociais, tais como Dr. Amie Breeze Harper, Kimberly Elise, Angela Davis, Bryant Terry, Syl Ko, Aph Ko, Venus Williams, Erykah Badu, Carl Lewis, Tracye McQuirter, Monique Koch, Ray Stone, John Lewis e entre outros mais, assumiram esse papel ao criarem e recriarem um mundo vegano para si mesmos.

\section{REFERÊNCIAS}

ADAMS, C. J. A política sexual da carne: Uma teoria feminista-vegetariana. 2. ed. São Paulo: Alaúde Editorial, 2018.

ALVES, L. G; NEGRI, S. Abordagem sobre vegetarianismo na formação do profissional nutricionista. Disponível em: $<$ https://www.svb.org.br/publicacoes/trabalhos-academicos $>$. Acesso em: 17 nov. 2019.

ALBINO, A. V; SANTOS, D. M. SEGURANÇA ALIMENTAR E NUTRICIONAL NA ASSISTÊNCIA SOCIAL: Desafios e Perspectivas em uma Metrópole. II Congresso de Assistentes Sociais do Estado do Rio de Janeiro. p. 1-12, mai. 2016. Disponível em: < http://www.cressri.org.br/site/wp-content/uploads/2016/05/016.pdf>. Acesso em: 17 nov. 2019.

BRAZ, M. Mudanças no perfil das lutas de classes e modismos conceituais: o tormento de Sísifo das Ciências Sociais. São Paulo: Cortez, 2012.

CONSEA. Política Nacional de Segurança Alimentar e Nutricional - Proposições do Conselho Nacional de Segurança Alimentar e Nutricional para sua elaboração. 2009. Disponível em $<$ http://www4.planalto.gov.br/consea/eventos/plenarias/documentos/2009/proposicoe s-do-conselho-nacional-de-seguranca-alimentar-e-nutricional-para-elaboracao-da- 
politica-nacional-de-seguranca-alimentar-e-nutricional-08.2009>. Acesso em: 24 nov. 2019.

DOMINGUES, P. "Um desejo infinito de vencer": o protagonismo negro no pósabolição. Revista Topoi, v. 12, n. 23, jul.-dez. 2011, p. 118-139.

FILHOS DO CANDOMBLÉ. Os veganos no Candomblé. 2019. Disponível em: < https://contatofilhosdocan.wixsite.com/filhosdocandomble/blog/os-veganos-nocandomble>. Acesso em: 17 nov. 2019.

HOCHSCHARTNER, J. Vegan Angela Davis Connects Human and Animal Liberation. 2014. Disponível em: <https://www.counterpunch.org/2014/01/24/veganangela-davis-connects-human-and-animal-liberation/>. Acesso em: 13 nov. 2019.

JUSBRASIL. Não é fácil ser jovem, negra e vegana. 2015. Disponível em: $<$ https://anda.jusbrasil.com.br/noticias/171406109/nao-e-facil-ser-jovem-negra-evegana>. Acesso em: 13 nov. 2019.

LABORATÓRIO DE ÉTICA AMBIENTAL (LEA). Veganismo, por Angela Davis. Youtube, 18 nov. 2017.2 Disponível <https://www.youtube.com/watch?v=kBtBwZAou Y>. Acesso em: 15 nov. 2019

MODEFICA. 3 Motivos Pelos Quais Pessoas Negras Não Se Engajam No Movimento Dos Direitos Dos Animais. E Por Que Elas Deveriam. 2017. Disponível em: $\quad<$ https://www.modefica.com.br/movimento-negro-direitosanimais/\#.XdoNQOhKjIX>. Acesso em: 15 nov. 2019

NERY, N. RACISMO NO MOVIMENTO VEGANO. Youtube, 20 mai. 2019. Disponível em: <https://www.youtube.com/watch?v=0gOXmZqo6mY\&t=943s > Acesso em: 15 nov. 2019.

PENINA, M. Thallita Floripes: "sou vegana, feminista e preta". 2017. Disponível em: $<$ http://nosmulheresdaperiferia.com.br/noticias/thallita-floripes-sou-vegana-feministae-preta/>. Acesso em: 20 nov. 2019.

SANTOS, S. et al. Ações afirmativas: polêmicas e possibilidades sobre igualdade racial e o papel do Estado. Revista Estudos Feministas, Florianópolis, 16(3): 913929, set-dez/2008.

SOCIEDADE VEGETARIANA BRASILEIRA. Saúde. São Paulo.

SOCIEDADE VEGETARIANA BRASILEIRA. Pesquisa do IBOPE aponta crescimento histórico no número de vegetarianos no Brasil. São Paulo: 2018.

SEGURANÇA Alimentar e Nutricional. Secretaria do Estado da Assistência e Desenvolvimento Social do Estado de Alagoas. Disponível em: $<$ http://www.assistenciasocial.al.gov.br/programas-projetos/seguranca-alimentar-enutricional-1>. Acesso em: 24 nov. 2019.

TERTO, A. 'Black Vegans Rock': Conheça Aph Ko, ativista que luta pela presença negra dentro do movimento vegano. 2017. Disponível em: 
FELIPE, R.

A relação entre a luta antirracista, o veganismo e a política de assistência social

$<$ https://www.huffpostbrasil.com/2016/05/10/black-vegans-rock-conheca-aph-koativista-que-luta-pela-pres a 21695610/>. Acesso em: 19 nov. 2019. 